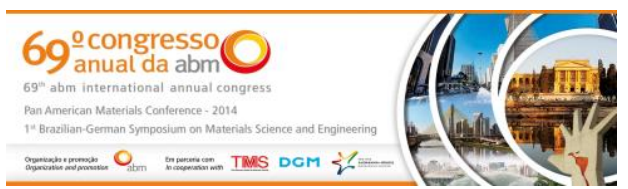

Tema: Metalurgia física e comportamento de materiais em temperaturas elevadas

\title{
CORRELAÇÃO ENTRE AS CURVAS DE ESCOAMENTO PLÁSTICO A QUENTE E AS MICROESTRUTURAS DO AÇO INOXIDÁVEL AUSTENÍTICO DUPLEX DIN W. NR. 14462
}

\author{
Mauro Araújo Medeiros ${ }^{1}$ \\ Samuel Filgueiras Rodrigues ${ }^{2}$ \\ Gedeon Silva Reis ${ }^{3}$
}

\section{Resumo}

Os aços inoxidáveis dupex tem sido largamente empregado em vários setores da industria principalmente em virtude da sua boa combinação entre suas propriedades mecânicas e resistência a corrosão. Um aço inoxidável duplex DIN W. Nr. 14462 foi submetido a ensaios de torção a quente com taxas de deformação de 0,$3 ; 0,5 ; 1 ; 3$ e $5 \mathrm{~s}^{-1}$ a temperaturas que variou entre 1.000 e $1.150^{\circ} \mathrm{C}$. As amostras deformadas foram analisas através de microscopia ótica. As configurações das curvas de escoamento plástico foram analisadas em termos dos parâmetros de fluxo localizado como um mecanismo de acomodação da deformação durante a torção a quente. As microestruturas reveladas mostraram que o comportamento plástico do material é influenciado pela disposição inicial das partículas de austenita na matriz ferrítica e a queda de tensão após o pico esta relacionada à ocorrência de fluxo localizado na matriz ferrítica associado à fragmentação das partículas de austenita durante o processamento, bem como aos fenômenos de recuperação e recristalização dinâmica, típicos dos aços inoxidáveis duplex.

Palavras-chave: aços inoxidáveis duplex; curvas de escoamento plástico; microscopia ótica.

\section{CORRELATION BETWEEN THE PLASTIC HOT FLOW CURVES AND THE MICROSTRUCTURE OF THE DUPLEX AUSTENITIC STAINLESS STEEL DIN W.}

\section{Abstract}

Nr. 1.4462

The dupex stainless steels have been widely used in various industries mainly because of its good combination of mechanical properties and corrosion resistance. A duplex stainless steel DIN W. Nr. 14462 was subjected to hot torsion test with strain rates of $0.3,0.5,1,3$ and $5 \mathrm{~s}^{-1}$ at temperatures range between 1,000 and $1,150^{\circ} \mathrm{C}$. Deformed samples were reviewest by optical microscopy. The configurations of the plastic flow curves were analyzed in terms of the flow parameters located as a mechanism of accommodation of deformation during hot torsion. The disclosed microstructures showed that the material plastic behavior is influenced by the initial arrangement of particles in austenite in a ferritic matrix and the stress drop after the peak is related to the occurrence of localized flow associated with the ferritic matrix of austenite particle fragmentation during processing, as well as the phenomena of recovery and dynamic recrystallization, typical of duplex stainless steels.

Keywords: Duplex stainless steels; Plastic flow curves; Optical microscopy.

1 Engenharia Mecânica, Doutor, Professor, Departamento de Mecânica e Materiais, Instituto Federal de Educação, Ciência e Tecnologia do Maranhão, IFMA, São Luís, MA, Brasil.

2 Física, Mestre, Professor, Departamento de Mecânica e Materiais, Instituto Federal de Educação, Ciência e Tecnologia do Maranhão, IFMA, São Luís, MA, Brasil.=

3 Engenharia Mecânica. Doutor. Professor. Departamento de Engenharia Mecânica e Materiais, Instituto Federal de Educação, Ciência e Tecnologia do Maranhão, IFMA, São Luís, MA, Brasil.

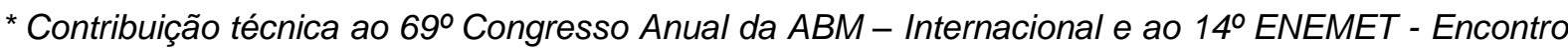
Nacional de Estudantes de Engenharia Metalúrgica, de Materiais e de Minas, 21 a 25 de julho de 2014, São Paulo, SP, Brasil. 


\section{INTRODUÇÃO}

Muitas vezes, a realização de ensaios termomecânicos enfrentam dificuldades relacionadas à composição química do material, bem como às suas características microestruturais como é o caso dos aços bifásicos, cuja combinação de duas fases, com propriedades diferentes, torna mais complexo a relação entre os mecanismos envolvidos no processamento a quente desse material. Um caso específico de aços bifásicos são os aços inoxidáveis dúplex, cuja importância se deve às suas excelentes combinações de propriedades tais como uma boa resistência mecânica associada a uma boa resistência à corrosão, que, contudo, necessitam de um cuidado especial durante o processamento mecânico a quente devido à existência de uma faixa de baixa ductilidade durante o trabalho, o que pode comprometer as propriedades finais esperadas. Diante dessas demandas, este trabalho tem como objetivo estudar a correlação entre a microestrutura e o escoamento plástico do aço inoxidável duplex DIN W. Nr. 1.4462, quando submetido ao trabalho a quente através de ensaios de torção, com aplicação dos parâmetros metalúrgicos para a verificação da ocorrência ou não do fenômeno de fluxo localizado na matriz ferritica. O encruamento é um dos mecanismos de endurecimento responsável pelo aumento da resistência mecânica dos materiais metálicos submetidos a operações de conformação mecânica. Em trabalhos de conformação a quente com metais e ligas, o encruamento acontece com o aumento da densidade de discordâncias, cujo empilhamento dificulta os seus deslocamentos na rede cristalina.

Grande parte da energia gasta para deformar um metal se perde em calor e uma pequena parte fica armazenada no metal. Desta, uma pequena fração é devida à deformação elástica, sendo a maior parte atribuída à criação de defeitos na rede cristalina tais como vacâncias, átomos intersticiais, discordâncias, falhas de empilhamento e maclas, onde cerca de 80 a $90 \%$ desta energia armazenada se deve à geração de discordâncias [1]. O aumento da temperatura gera a movimentação de discordâncias que estão imobilizadas. Discordâncias que são geradas e emaranhadas durante a deformação são, gradualmente, aniquiladas proporcionando os efeitos da recuperação. A presença de soluto impede a escalagem de discordâncias devido ao aumento na força de ligação entre átomos e vacâncias, porém permite a separação parcial das discordâncias em um trecho onde há falha de empilhamento, o que dificulta a escalagem e o deslizamento cruzado e, consequentemente, a recuperação. Um outro fator que retarda a recuperação é a presença de precipitados por tornar a estrutura mais estável [2].

Os mecanismos de amaciamento que atuam durante o processamento a quente de um material ou liga metálica são a recuperação e a recristalização dinâmica. Para um material metálico que se recupera dinamicamente sob condições em que a temperatura e taxa de deformação são constantes, tem-se a curva tensão versus deformação dividida em três estágios. O comportamento da curva no estágio inicial apresenta um aumento rápido de tensão, onde o material sofre apenas microdeformações. Nesse estágio, a taxa de deformação varia de zero até o valor imposto ao teste, fazendo com que a densidade de discordâncias aumente da ordem de $10^{10}$ até $10^{12} / \mathrm{m}^{2}$. A partir desse ponto, inicia-se o segundo estágio caracterizado pelo encruamento gerado pelo emaranhamento das discordâncias, produzindo uma estrutura celular. Ainda nessa fase inicia-se 0 escoamento plástico com 0 decréscimo do coeficiente de encruamento dando início ao terceiro estágio denominado estado estacionário, onde a curva passa a não ter mais inclinação mantendo os parâmetros tensão, temperatura e taxa de deformação constantes.

\footnotetext{
* Contribuição técnica ao $69^{\circ}$ Congresso Anual da ABM - Internacional e ao 14ํㅡㄹ ENEMET - Encontro Nacional de Estudantes de Engenharia Metalúrgica, de Materiais e de Minas, 21 a 25 de julho de 2014, São Paulo, SP, Brasil.
} 


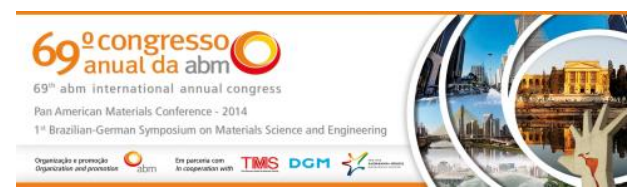

Esse estágio é caracterizado pelo equilíbrio dinâmico entre as taxas de geração e aniquilação de discordâncias, onde os grãos são alongados e os subgrãos são equiaxiais com tamanhos estáveis mesmo em grandes deformações [3].

No caso da recristalização dinâmica, as discordâncias formam arranjos planares que dificultam a sua mobilidade, havendo um desequilíbrio entre a taxa de geração e de aniquilação de discordâncias fazendo com que a tensão aumente no estágio inicial da deformação, onde a subestrutura desenvolvida é pouco recuperada. A recristalização dinâmica surge quando em um material metálico a escalagem e o deslizamento cruzado de discordâncias não operarem mais de maneira efetiva, devido à baixa mobilidade de discordância durante a deformação a quente. Neste caso, tem-se a formação de uma subestrutura de arranjos planares de discordância que não é completamente recuperada durante a deformação. Assim, as células têm tamanhos relativamente menores e suas paredes são mais emaranhadas quando comparadas com metais que sofrem alto grau de recuperação dinâmica [4].

Equações constitutivas incluindo o termo de Arrênius têm sido aplicadas para os aços com o objetivo de calcular as forças de laminação e forjamento a quente. A função relativa à tensão e taxa de deformação é geralmente a do seno hiperbólico desde que a força e as leis exponenciais apareçam linearmente em tensões altas e baixas respectivamente [5]. À elevada temperaturas, o comportamento de escoamento de materiais policristalinos pode ser descritos pela clássica relação hiperbólica do seno:

$$
\varepsilon=\mathrm{A}(\sinh \alpha \sigma)^{n} \exp \left(\frac{-Q}{R T}\right)
$$

onde $\mathrm{A}$, $\alpha$ e $\mathrm{n}$ são as constantes, $\mathrm{Q}$ a energia de ativação para o trabalho aquente , $\varepsilon$ e $\sigma$ a taxa de deformação e tensão verdadeiras envolvidas respectivamente, $\mathrm{T}$ a temperatura e R a constante universal dos gases.

Os fenômenos que ocorrem durante a deformação são termicamente ativados. Sendo assim, pode-se compensar o efeito da temperatura e da taxa de deformação através do parâmetro de Zenner-Hollomon(Z), que é uma forma diferenciada de apresentação da equação acima citada [6]:

$$
Z=\dot{\varepsilon} \exp \left(\frac{Q}{R T}\right)=\mathrm{A}\left[\operatorname{senh}(\alpha \sigma)^{n}\right]
$$

Em materiais com média e baixa energia de falha de empilhamento, a recristalização é responsável pelo amaciamento, uma vez que nestes materiais os mecanismos de escalagem e deslizamento cruzado de discordâncias são dificultados [7].

\subsection{Características das Microestruturas Bifásicas}

Quando se investiga a deformação a quente de um metal ou liga, objetiva-se obter informações sobre a microestrutura que determina o comportamento do material durante 0 processamento, bem como as propriedades do produto final. As características da microestrutura têm influência direta no comportamento desses materiais quando deformados plasticamente.

Dentre outros defeitos, os mais evidentes na composição de uma microestrutura são as vacâncias, discordâncias, contornos de grão, poros, partículas e interfaces. É a partir da mensuração de aspectos relativos a esses defeitos, tais como número, comprimento, área e volume, que se estabelece a caracterização de uma microestrutura.

\footnotetext{
* Contribuição técnica ao 69ำ Congresso Anual da ABM - Internacional e ao 14ํㅡㄹ ENEMET - Encontro Nacional de Estudantes de Engenharia Metalúrgica, de Materiais e de Minas, 21 a 25 de julho de 2014, São Paulo, SP, Brasil.
} 


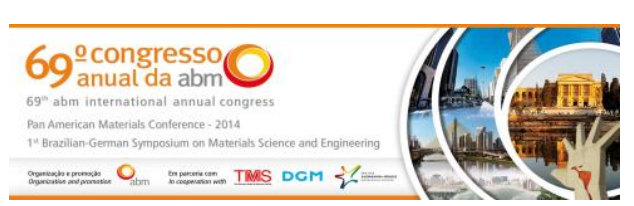

No caso das microestruturas bifásicas, Hornbogen [8] define três tipos elementares: dispersão, rede e duplex, em função da fração volumétrica, forma e distribuição das fases presentes. Estes tipos de microestrutura bifásica estão ilustrados na figura 1.

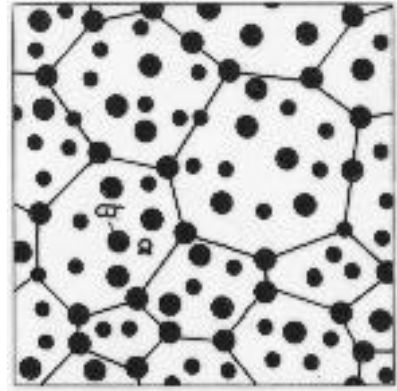

(a)

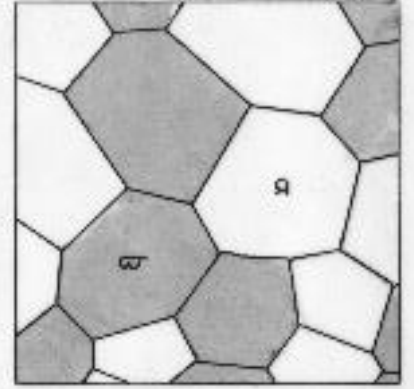

(b)

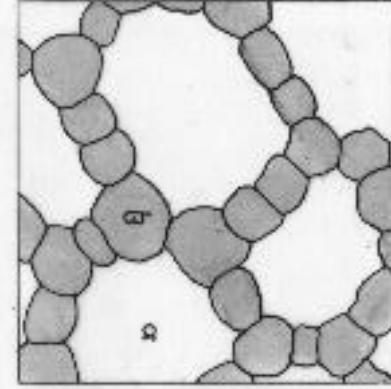

(c)

Figura 1. llustração esquemática dos diferentes tipos de estrutura bifásica: (a) dispersão, (b) duplex e (c) estrutura de rede [8].

Os parâmetros metalúrgicos impostos sobre o processamento termomecânico repercutem nas características da microestrutura bifásica que pode sofrer mudanças de acordo com a taxa e temperatura de deformação, tratamentos térmicos e velocidade de resfriamento. São transformações de caráter contínuo ou descontínuo e que levam ao aparecimento ou desaparecimento de um ou outro tipo particular de contorno ou interface. Como exemplo, a figura 2 ilustra transformações microestruturais do tipo dispersão $\leftrightarrow$ rede, dúplex $\leftrightarrow$ dispersão [8].
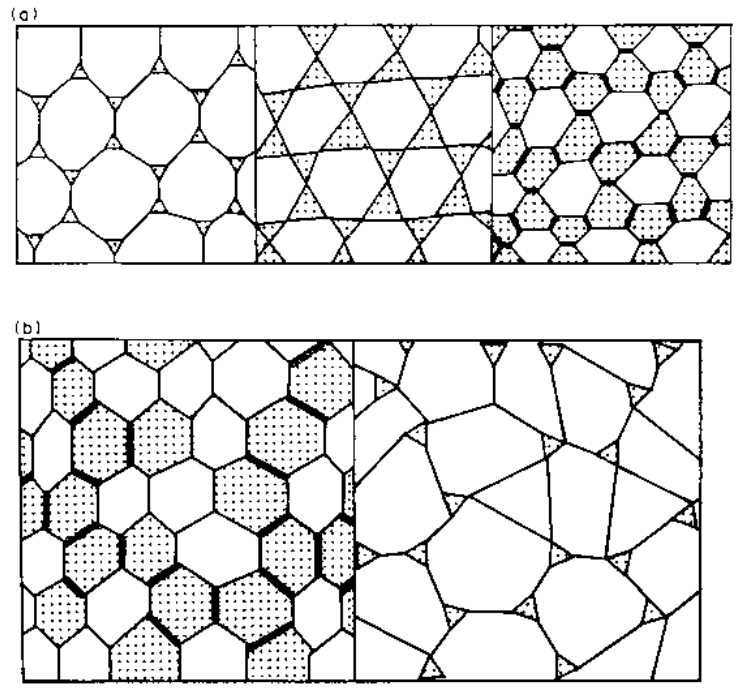

Figura 2. Transformações que podem ocorrer entre os tipos de microestruturas: a) dispersão $\leftrightarrow$ rede, b) duplex $\leftrightarrow$ dispersão [8].

Quando um material bifásico é submetido a trabalho de conformação, as propriedades de cada uma das fases constituintes e as frações volumétricas de ambas, além de outros aspectos relacionados às microestruturas e interfaces, são os principais fatores que determinam como esse material se comporta frente aos esforços a que está sendo submetido [7].

\footnotetext{
* Contribuição técnica ao 69 Congresso Anual da ABM - Internacional e ao 14ํㅡㄹ ENEMET - Encontro Nacional de Estudantes de Engenharia Metalúrgica, de Materiais e de Minas, 21 a 25 de julho de 2014, São Paulo, SP, Brasil.
} 


\subsection{Deformação a Quente dos Aços Inoxidáveis Duplex}

Durante a deformação a quente de materiais polifásicos, o comportamento mecânico depende das características plásticas de cada uma das fases, das proporções, distribuições e formas das fases, além da natureza dos contornos que separam estas fases. Quando duas fases são deformadas juntas, a deformação das fases não tem uma distribuição uniforme. No caso dos aços inoxidáveis duplex, costuma haver uma concentração de deformação inicialmente na fase mais macia, no caso, a própria fase ferrítica. Com a continuação do processo, pode haver um decréscimo nos gradientes de deformação como resultado de mecanismos de acomodação como recuperação e recristalização, bem como o deslizamento de interfaces e contornos de grãos.

A despeito do complexo comportamento de deformação plástica dos aços inoxidáveis duplex, tem sido encontrado que a fase ferrítica continua a exibir uma intensa recuperação dinâmica, enquanto que a fase austenítica sofre recristalização dinâmica [9]. Cizek e Wynne [10] realizando testes de torção a quente em aços inoxidáveis duplex, encontraram que a matriz ferrítica amacia por recuperação dinâmica estendida (ou recristalização dinâmica contínua) e a curva de escoamento é caracterizada por um pico moderado de tensão, sendo que junto com esse resultado, observada uma pequena quantidade de grãos recristalizados dinamicamente na fase austenítica. Durante a deformação a quente dos aços inoxidáveis dúplex, os mecanismos de endurecimento e amaciamento atuam de forma diferente em cada uma das fases. Por exemplo, o amaciamento da ferrita, que possui alta energia de falha de empilhamento, ocorre essencialmente por recuperação dinâmica em baixas deformações, gerando uma subestrutura de subgrãos. Já na austenita, que tem baixa energia de falha de empilhamento, a região de encruamento é mais extensa, com maior acúmulo de energia interna, tendendo a levar o material à recristalização dinâmica [11].

Embora a atenção tenha sido focada nos mecanismos de amacimento operando nas fases ferrítica e austenítica, poucos estudos sistemáticos têm sido conduzidos para identificar as relações entre a microestrutura e a forma das curvas de escoamento desses aços quando as condições de deformação e a composição química são alteradas [9].

\section{MATERIAIS E MÉTODOS}

\subsection{Material Utilizado}

Para a realização deste trabalho utilizou-se o aço inoxidável duplex DIN W. Nr. 1.4462, fornecido em barras cilíndricas pela empresa Fundinox, com diâmetro de $110 \mathrm{~mm}$ e comprimento de $230 \mathrm{~mm}$. A tabela 1 traz informações sobre a composição química desse aço.

Tabela 1. Composição química do aço duplex estudado (\% em peso)

\begin{tabular}{cccccccccc}
$\mathbf{C}$ & $\mathbf{S i}$ & $\mathbf{M n}$ & $\mathbf{C r}$ & $\mathbf{M o}$ & $\mathbf{N i}$ & $\mathbf{P}$ & $\mathbf{S}$ & $\mathbf{N}$ & $\mathbf{F e}$ \\
\hline 0,037 & 0,48 & 1,80 & 22,2 & 3,03 & 5,58 & 0,022 & 0,002 & 0,12 & bal \\
\hline
\end{tabular}

\footnotetext{
* Contribuição técnica ao $69^{\circ}$ Congresso Anual da ABM - Internacional e ao 14ํㅡㄹ ENEMET - Encontro Nacional de Estudantes de Engenharia Metalúrgica, de Materiais e de Minas, 21 a 25 de julho de 2014, São Paulo, SP, Brasil.
} 


\subsection{Ensaios de Torção a Quente}

Os ensaios de torção a quente foram realizados utilizando-se a máquina horizontal de ensaios de torção a quente que está conectada com um microcomputador, o que possibilita o controle do ensaio e a aquisição de dados.

Essa máquina é equipada com um motor servo elétrico de 6 KVA com velocidade variável de 1 a 2000 rpm, que aplica os esforços mecânicos às amostras. Uma célula de carga com capacidade de $1000 \mathrm{kgf.cm}$ é utilizada para medir tais esforços. A forma de aquecimento a ser utilizada depende das temperaturas envolvidas e das taxas de aquecimento e de resfriamento a serem aplicadas. Nos ensaios realizados neste trabalho utilizamos o forno de radiação, que tem potência máxima de $6 \mathrm{KW}$, onde os corpos de prova são envolvidos por um tubo de quartzo, dentro do qual circula gás argônio, para proteção contra a oxidação durante os ensaios. Através deste tubo é injetada água logo após o término de cada ensaio, para o "congelamento" das microestruturas. A temperatura dos ensaios é medida através de um termopar tipo $\mathrm{K}$ com cobertura de aço inoxidável que é inserido em um furo na extremidade de rosca do corpo de prova. Os controles da temperatura do ensaio, da taxa de aquecimento, de resfriamento e do tempo de encharque são feitos utilizando-se um controlador de temperatura modelo Eurotherm 2408. Um computador interligado à máquina realiza a aquisição dos dados por meio de um programa especialmente desenvolvido para este tipo de ensaio.

Os gráficos tensão-deformação equivalentes são utilizados para apresentar as respostas do material às solicitações mecânicas. Medidas do ângulo de rotação realizadas pelo transdutor de rotação são utilizadas para calcular a deformação e a taxa de deformação. O ângulo de rotação da máquina é calculado pela relação:

$$
\theta=\frac{2 \pi}{90} \cdot l
$$

sendo / a leitura registrada.

Para a deformação equivalente utiliza-se a equação:

$$
\varepsilon=\frac{R \cdot \theta}{\sqrt{3} \cdot L}
$$

onde $L$ é o comprimento útil do corpo de prova. A taxa de deformação é calculada dividindo a deformação pelo tempo total do ensaio.

A tensão equivalente é calculada utilizando a equação:

$$
\sigma=\frac{\sqrt{3} \cdot M}{2 \cdot \pi \cdot R^{3}}(3+m+n)
$$

onde Mé o momento torsor, Ré o raio do corpo de prova e $m$ e $n$ são os coeficientes de sensibilidade do material à taxa de deformação e ao encruamento, respectivamente, sendo que $n$ é o coeficiente que está relacionado com a inclinação da curva $\ln M x \ln \theta$. O coeficiente de sensibilidade à taxa de deformação é determinado através das inclinações da curva $\log M \times \log \dot{\varepsilon}$.

\subsection{Ensaios de Torção a Quente Realizados}

Inicialmente, foram realizados dez ensaios de torção isotérmicos e contínuos até a fratura. Esses ensaios foram realizados em aquecimento conforme ilustrado na figura 3 , sendo cinco com o aço laminado a quente e a frio e cinco com o aço

\footnotetext{
* Contribuição técnica ao $69^{\circ}$ Congresso Anual da ABM - Internacional e ao 14ํㅡㄹ ENEMET - Encontro Nacional de Estudantes de Engenharia Metalúrgica, de Materiais e de Minas, 21 a 25 de julho de 2014, São Paulo, SP, Brasil.
} 


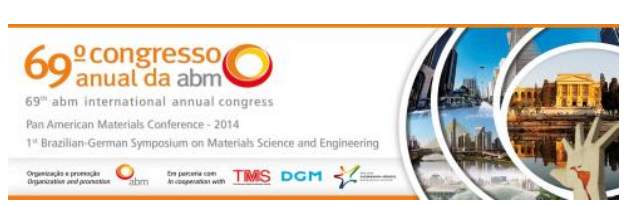

laminado a quente e tratado termicamente. Em ambos os casos, os ensaios foram feitos a uma temperatura de $1150^{\circ} \mathrm{C}$ com tempo de encharque de um minuto, obedecendo a uma seqüência de taxas de deformações de 0.3, 0.5, 1.0, 3.0 e 5.0 $\mathrm{s}^{-1}$. Tais ensaios tiveram o intuito de revelar uma microestrutura percolada, no caso do laminado e dispersa no caso do tratado, alem de apresentar curvas de escoamento plástico com características que possibilitasse o cálculo de parâmetros de indicação de fluxo localizado nas amostras ensaiadas.

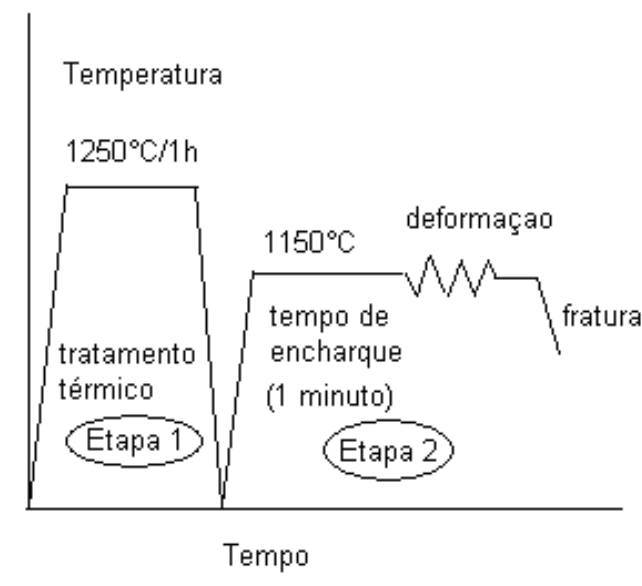

(a)

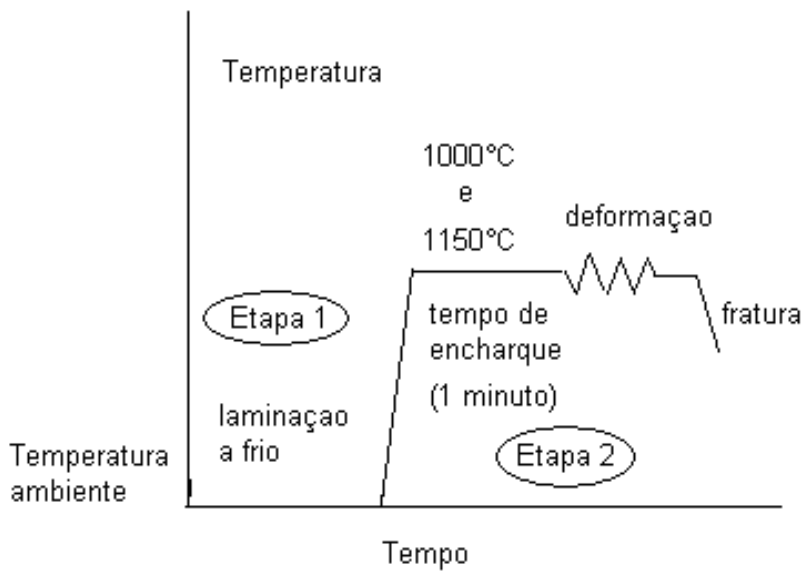

(b)

Figura 3. Representação esquemática dos ensaios realizados sendo a) para o aço tratado termicamente e b) para o aço laminado a frio.

Em uma segunda etapa do trabalho, foram realizados mais 8 ensaios com o aço laminado a frio, cuja temperatura de ensaio foi de $1000^{\circ} \mathrm{C}$ com tempo de encharque de um minuto (figura $3 \mathrm{~b}$ ) e taxa de deformação igual a $1 \mathrm{~s}^{-1}$, seguindo uma seqüência de deformações com valores de $0.1,0.3,0.5,0.75,1.0,2.0$, e 3.0.

\subsection{Procedimento para Análise da Microestrutura}

A captura das microestruturas foi feita de maneira que se obtivesse imagens que varressem toda superfície de cada amostra, obedecendo-se a um critério de alinhamento, onde a borda lateral inferior da parte visível das amostras embutidas foram dispostas de forma paralela à borda lateral inferior da bandeja do microscópio, possibilitando um acompanhamento da evolução microestrutural relativa as deformações executadas nos corpos de prova. A captura de diversas imagens por amostra possibilitou a seleção das imagens que melhor representassem 0 comportamento microestrutural, onde foi possível filtrar as imagens que apresentaram algum tipo de defeito relativo às fases de lixamento, polimento e ataque.

\section{RESULTADOS E DISCUSSÃO}

As amostras foram submetidos a dois tipos de processamento diferentes, com o objetivo de se obter dois tipos de microestrutura diferentes, sendo uma com as partículas de austenita percolando toda a matriz ferrítica (figura 4a) e a outra com as partículas de austenita se apresentando de forma dispersa na matriz ferrítica (figura 5a). Foi considerado como microestrutura inicial, aquela submetida à temperatura e tempo de encharque do ensaio de torção, mais que não sofreu os efeitos da

\footnotetext{
* Contribuição técnica ao 69ำ Congresso Anual da ABM - Internacional e ao 14ํㅡㄹ ENEMET - Encontro Nacional de Estudantes de Engenharia Metalúrgica, de Materiais e de Minas, 21 a 25 de julho de 2014, São Paulo, SP, Brasil.
} 


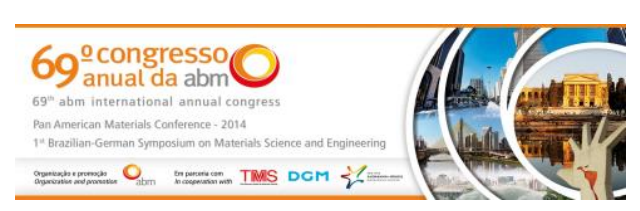

deformação originados pela torção. A obtenção da microestrutura inicial foi possível a partir de amostras retiradas de partes dos corpos de prova, fora do limite da área útil que sofreu a torção. As figuras $4 \mathrm{~b}$ e $5 \mathrm{~b}$ mostram as microestruturas iniciais do aço duplex estudado laminado a frio e tratado termicamente, respectivamente.

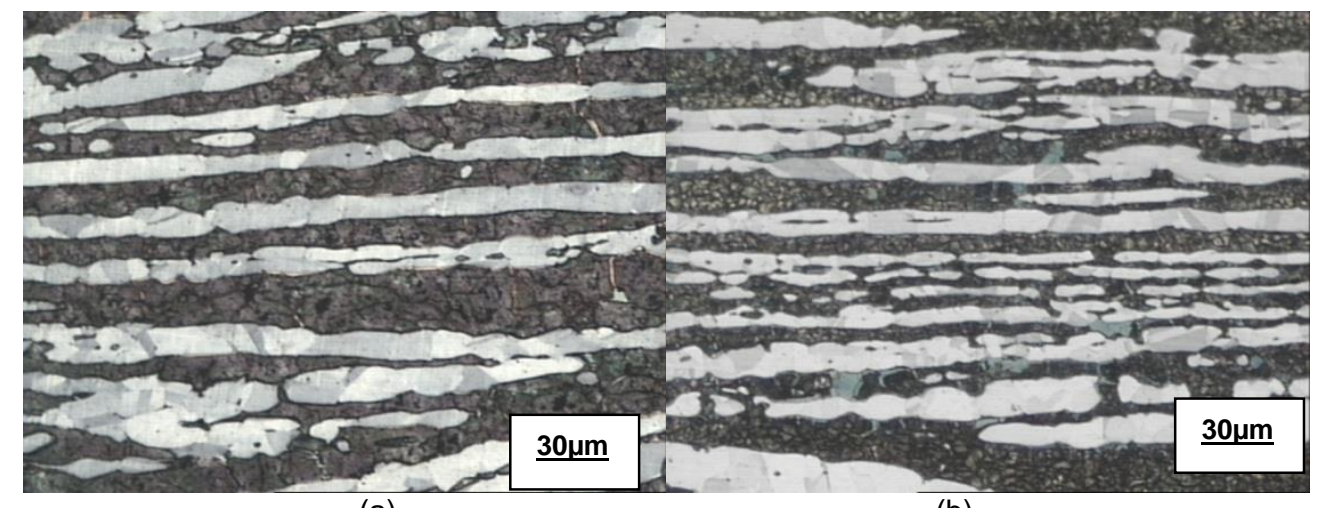

(a)

(b)

Figura 4. a) Microestrutura do material de partida e b) microestrutura inicial do aço laminado a frio e aquecido na temperatura de $1150^{\circ} \mathrm{C}$, sem deformação.

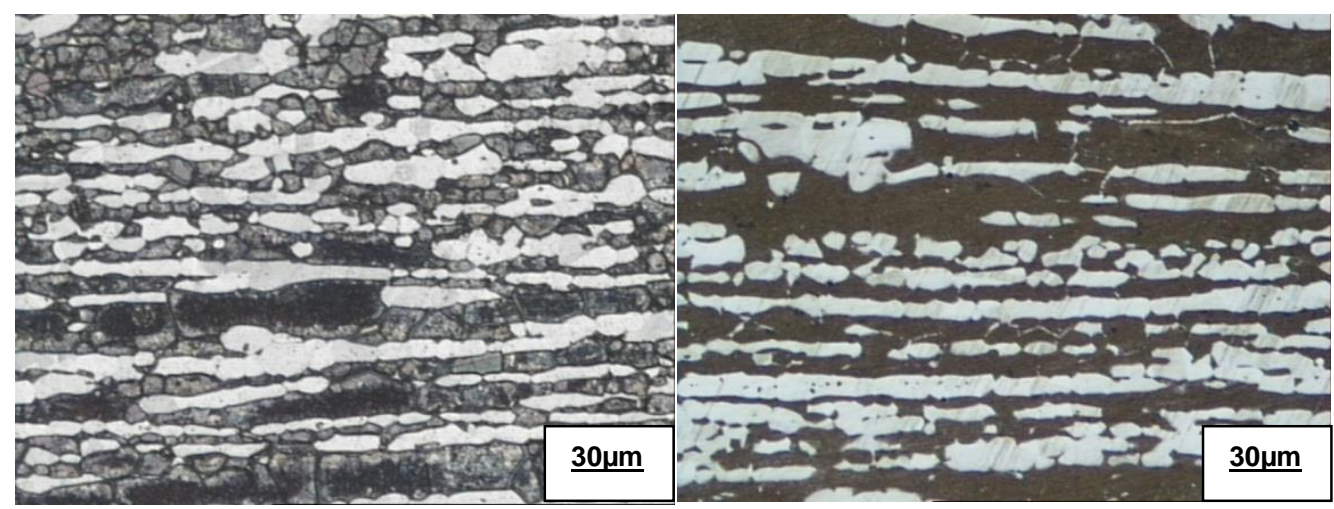

(a)

(b)

Figura 5. a) Microestrutura do material de partida e b) microestrutura inicial do aço tratado termicamente e aquecido na temperatura de $1150^{\circ} \mathrm{C}$, sem deformação.

As microestruturas referentes aos ensaios realizados a $1150^{\circ} \mathrm{C}$ com taxas de deformação de 3 e $5 \mathrm{~s}^{-1}$ são mostradas nas figuras 6 e 7 , respectivamente. As curvas referentes a essas microestruturas estão apresentadas na figura 8 onde percebe-se um patamar de pico de tensão superior ao dos ensaios realizados com taxas de 0.3 , 0.5 , e $1 \mathrm{~s}^{-1}$, cuja microestrutura correspondente é formada por camadas intercaladas de ferrita e austenita. Nota-se que existe uma extensa região de encruamento até o pico e em seguida o material fratura com uma pequena deformação de amaciamento.

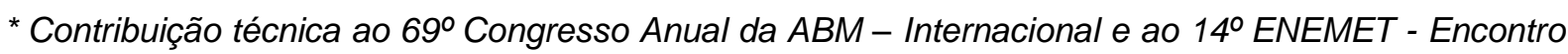
Nacional de Estudantes de Engenharia Metalúrgica, de Materiais e de Minas, 21 a 25 de julho de 2014, São Paulo, SP, Brasil.
} 

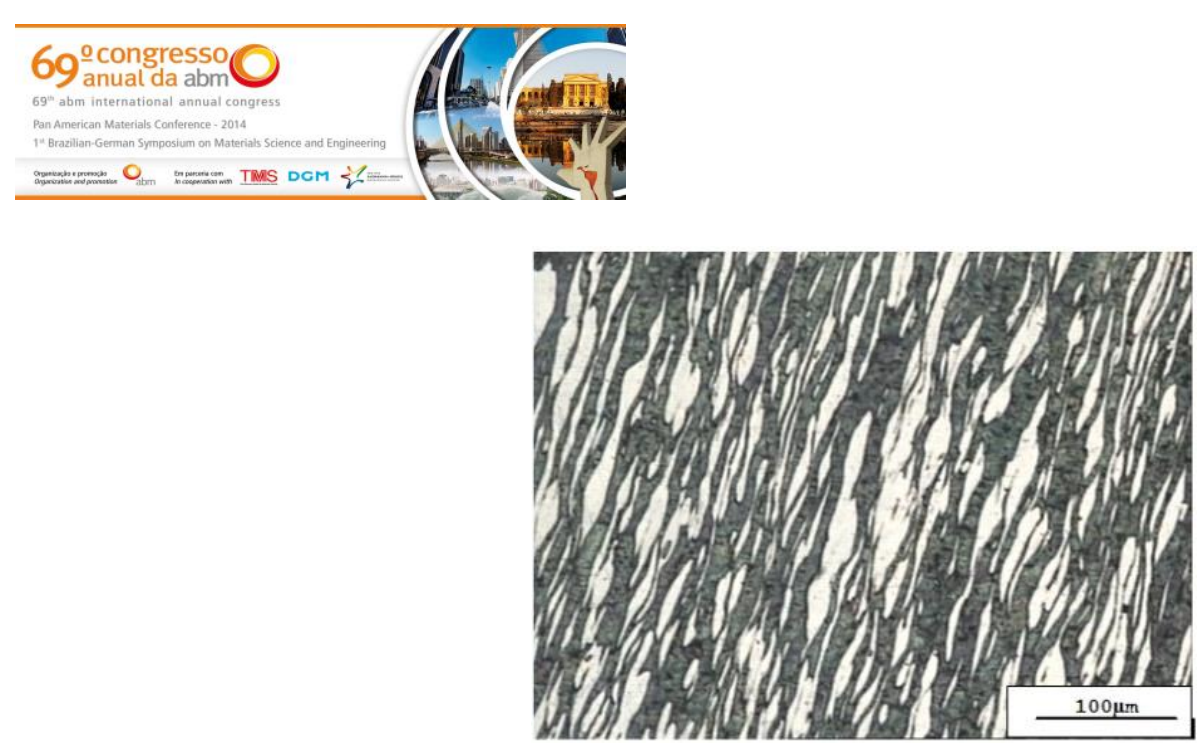

Figura 6. Microestrutura relativa ao ensaio realizado a $1150^{\circ} \mathrm{C} \operatorname{com}$ taxa de deformação de $3 \mathrm{~s}^{-1}$, utilizando o aço laminado a frio com $\varepsilon_{f}=1,5$.

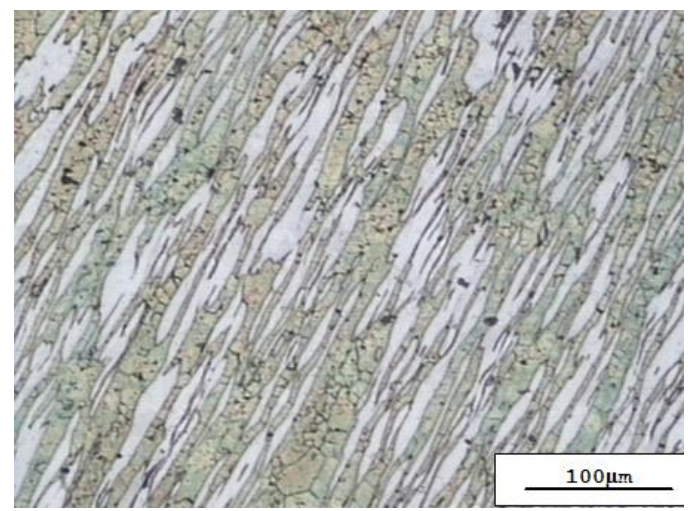

Figura 7. Microestrutura relativa ao ensaio realizado a $1150^{\circ} \mathrm{C} \mathrm{com} \mathrm{taxa} \mathrm{de} \mathrm{deformação} \mathrm{de} 5 \mathrm{~s}^{-1}$, utilizando o aço laminado a frio com $\varepsilon_{f}=1,73$.

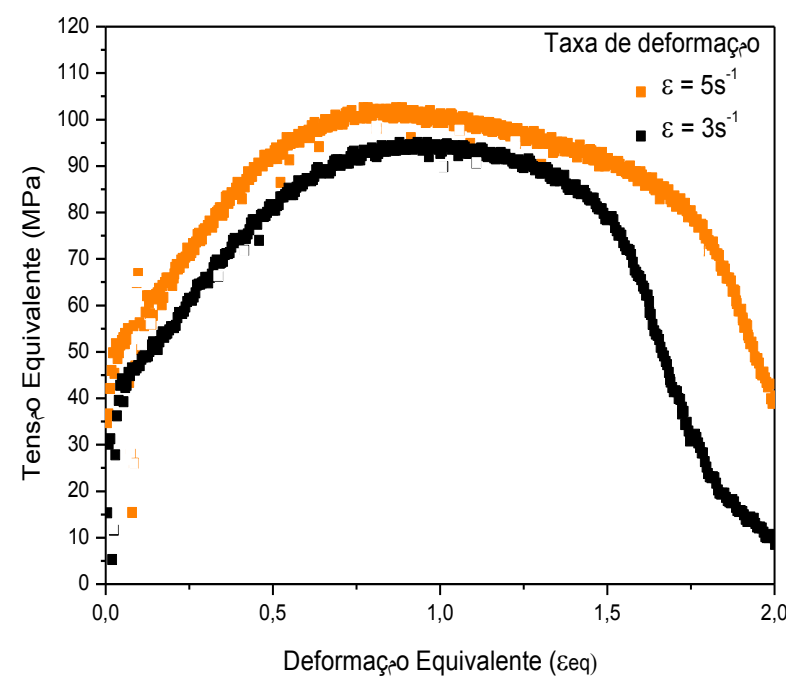

Figura 8. Curvas de escoamento plástico obtidas a partir dos ensaios realizados a $1150^{\circ} \mathrm{C}$ com taxas de 3 e $5 \mathrm{~s}^{-1}$ utilizando o aço laminado a frio.

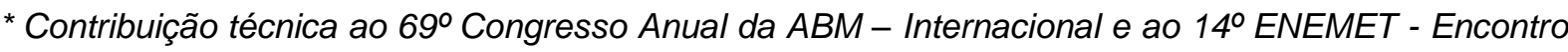
Nacional de Estudantes de Engenharia Metalúrgica, de Materiais e de Minas, 21 a 25 de julho de 2014, São Paulo, SP, Brasil.
} 


\subsection{Curvas de Escoamento Plástico do Aço Duplex que foi Laminado a Frio e Ensaiado a $1150^{\circ} \mathrm{C}$ com Taxas Variando de 0,3 a $5 \mathrm{~s}^{-1}$}

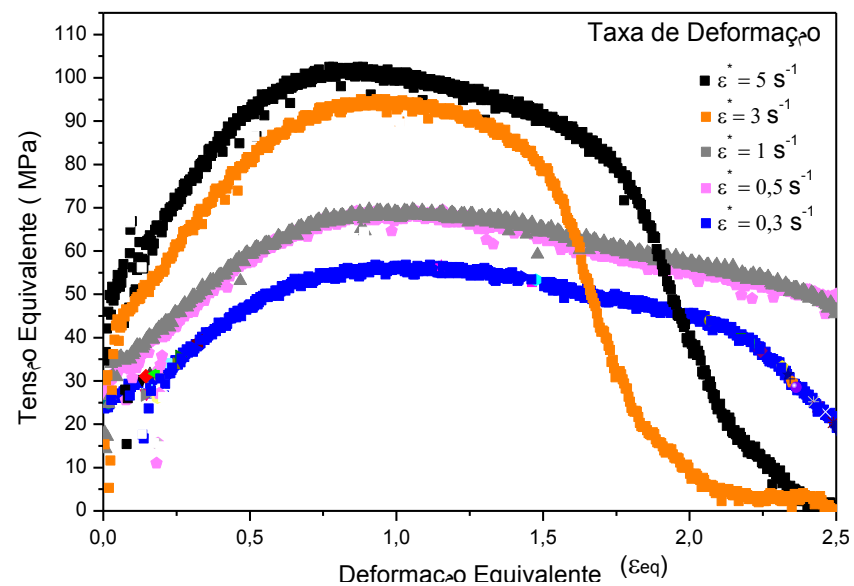

Figura 9. Curvas de escoamento plástico obtidas a partir dos ensaios realizado a $1150^{\circ} \mathrm{C}$ com o aço laminado a frio.

Tabela 2. Evolução da tensão equivalente $\sigma(\mathrm{MPa})$ com a deformação equivalente $\varepsilon$ e taxa de deformação $\varepsilon\left(\mathrm{s}^{-1}\right)$ medidas nas curvas de escoamento plástico da figura 9 referente ao aço laminado a frio.

\begin{tabular}{|c|c|c|c|c|c|}
\hline $\begin{array}{c}\text { Taxa de } \\
\text { Deformação } \\
\varepsilon\end{array}$ & \multicolumn{5}{|c|}{ Deformação equivalente $(\varepsilon)$} \\
\hline & 0,5 & 1 & 1,5 & 2 & 2,5 \\
\hline 0,3 & 47,742 & 56,2272 & 52,7766 & 45,1967 & \\
\hline 0,5 & 59,112 & 66,9183 & 63,2415 & 56,2272 & 46,3211 \\
\hline 1 & 59,112 & 69,7466 & 65,6738 & 57,3020 & 48,7011 \\
\hline 3 & 81,795 & 94,4053 & 79,6914 & & \\
\hline 5 & 92,825 & 100,9918 & 91,9210 & & \\
\hline & $\uparrow(\sigma)$ & $\uparrow(\sigma)$ & $\uparrow(\sigma)$ & $\uparrow(\sigma)$ & $\uparrow(\sigma)$ \\
\hline
\end{tabular}

Tabela 3. Valores do logaritmo da tensão equivalente $\sigma(\mathrm{MPa})$ em função da deformação equivalente $\varepsilon$ e do logaritmo da taxa de deformação calculados a partir da tabela 2

\begin{tabular}{|c|c|c|c|c|c|}
\hline $\begin{array}{c}\text { Ln(Taxa de } \\
\text { Deformação } \\
\left.\varepsilon \text { s }^{-1}\right)\end{array}$ & \multicolumn{5}{|c|}{ Deformação Equivalente $(\varepsilon)$} \\
\hline & 0,5 & 1 & 1,5 & 2 & 2,5 \\
\hline$-1,20397$ & 3,865 & 4,0294 & 3,9660 & 3,8110 & \\
\hline$-0,69315$ & 4,079 & 4,2034 & 4,1469 & 4,0294 & 3,8356 \\
\hline 0 & 4,079 & 4,2449 & 4,1847 & 4,0483 & 3,8857 \\
\hline 1,098612 & 4,404 & 4,5476 & 4,3781 & & \\
\hline 1,609438 & 4,530 & 4,6150 & 4,5209 & & \\
\hline & & $\uparrow \operatorname{Ln}(\sigma)$ & $\uparrow \operatorname{Ln}(\sigma)$ & $\uparrow \operatorname{Ln}(\sigma)$ & $\uparrow \operatorname{Ln}(\sigma)$ \\
\hline
\end{tabular}

* Contribuição técnica ao 69 Congresso Anual da ABM - Internacional e ao 14ํㅡㄹ ENEMET - Encontro Nacional de Estudantes de Engenharia Metalúrgica, de Materiais e de Minas, 21 a 25 de julho de 2014, São Paulo, SP, Brasil. 

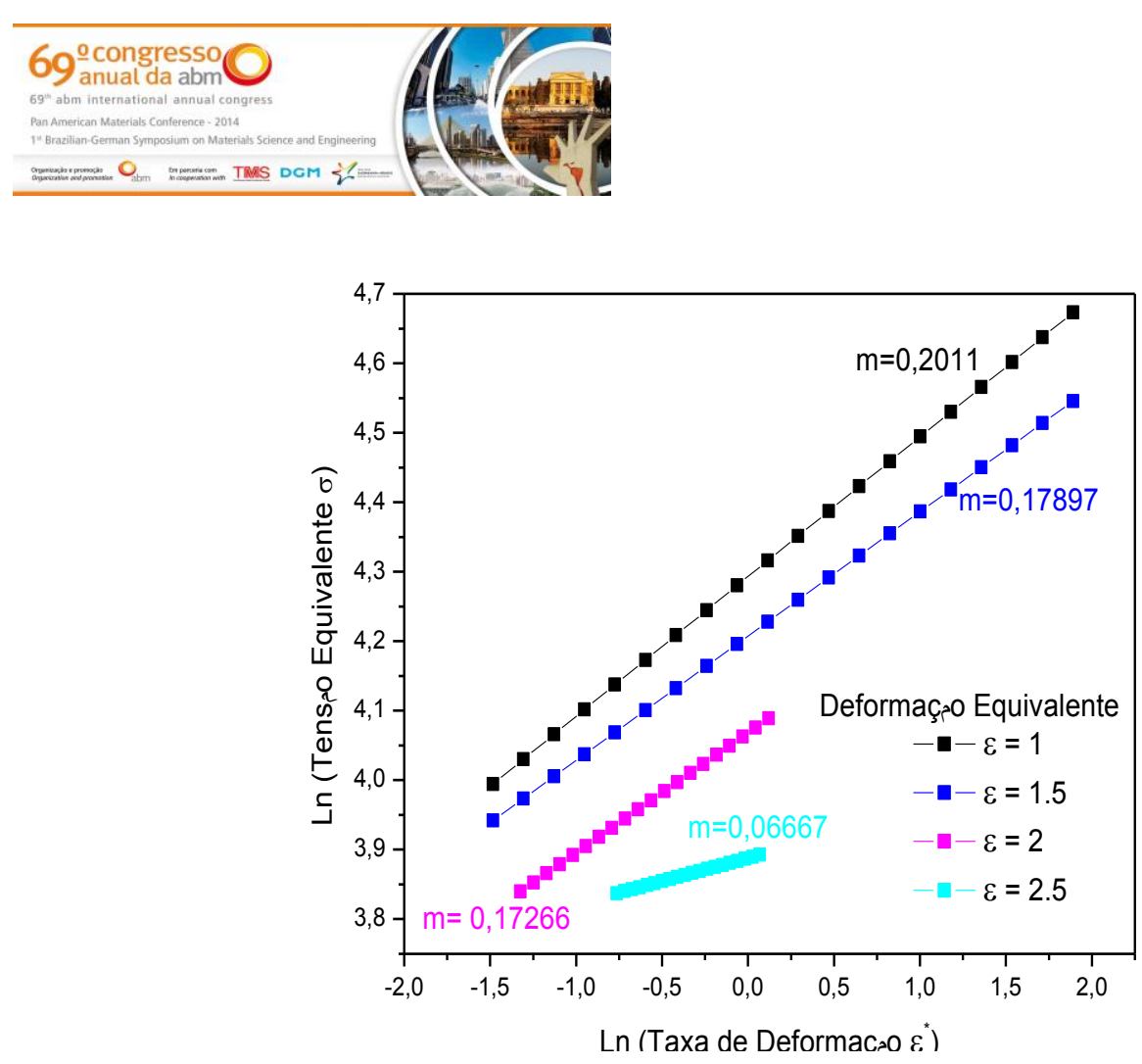

Figura 10. Valores do logaritmo da tensão equivalente aplicada variando em função do logaritmo da taxa de deformação referentes à tabela 3 , onde $m$ é a inclinação das retas $\operatorname{Ln}(\sigma) \times \operatorname{Ln}(\dot{\varepsilon})$.

Nos estágios iniciais da deformação plástica a fase ferrítica acomoda a maior parte da deformação, havendo em seguida uma transferência de carga da ferrita para a austenita, promovendo um maior endurecimento do material e uma deformação simultânea das duas fases levando ao alongamento das partículas de austenita e, consequentemente, à sua fragmentação.

As partículas de austenita se inclinam em relação ao eixo de rotação à medida que são alongadas, como conseqüência do modo de deformação atuante, onde uma das extremidades gira enquanto a outra permanece fixa.

A fase ferrítica é mais dúctil que a fase austenítica quando submetidas à deformação a quente em condições similares. Sabe-se ainda que as tensões de início de escoamento plástico da ferrita e do aço dúplex são próximas, indicando que, no caso do duplex, a deformação se concentra na matriz ferrítica no início do ensaio, levando a ocorrência de fluxo localizado na mesma que é mais macia do que a fase austenítica [1].

\section{CONCLUSÕES}

Os ensaios feitos utilizando microesturutras iniciais diferentes, demonstraram que o comportamento das curvas de escoamento plástico sofre influência da disposição inicial das partículas de austenita na matriz ferrítica e dos parâmetros metalúrgico. Foi observado e quantificado que para a microestrutura com austenita grosseiramente dispersa e percolada do aço inoxidável duplex DIM W. Nr. 1.4462, tratado termicamente a $1250^{\circ} \mathrm{C}$, ensaiado a $1150^{\circ} \mathrm{C}$ e deformado com taxa de deformação acima de $1 \mathrm{~s}^{-1}$, o fenômeno de fluxo localizado não foi evidenciado.

A queda de tensão após o pico, observada nas curvas de escoamento plástico, esta relacionada à ocorrência de fluxo localizado na matriz ferrítica associado à fragmentação das partículas de austenita durante o processamento, bem como aos fenômenos de recuperação e recristalização dinâmica, típicos dos aços inoxidáveis duplex. Houve surgimento de cavidades em junções tríplices e paralelas das

\footnotetext{
* Contribuição técnica ao 69ำ Congresso Anual da ABM - Internacional e ao 14ํㅡㄹ ENEMET - Encontro Nacional de Estudantes de Engenharia Metalúrgica, de Materiais e de Minas, 21 a 25 de julho de 2014, São Paulo, SP, Brasil.
} 


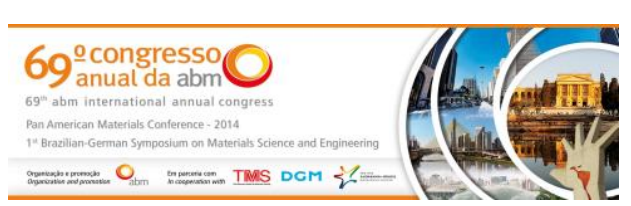

interfaces das fases austeníticas e ferríticas, como conseqüência do acúmulo de deformação nas mesmas.

\section{Agradecimentos}

Ao programa de Pós-Graduação em Engenharia de Materiais do IFMA. Ao Professor Doutor Oscar Balancin.

\section{REFERÊNCIAS}

1 Moretti CC. Estudo da trabalhabilidade a quente através do ensaio de torção [dissertação de mestrado]. São Carlos: Universidade Federal de São Carlos; 1989.

2 Hoffmann WAM. Estudo da trabalhabilidade a quente de um aço inoxidável austenítico (ABNT 304) e ligas a base de níquel através do ensaio de torção [dissertação de mestrado]. São Carlos: Universidade Federal de São Carlos; 1992.

3 Jonas $\mathrm{JJ}$, Mcqueen $\mathrm{HJ}$. Recovery and recrystallization during high temperature deformation. In: AVENAS, P. et al., orgs., Mise en forme des métaux et alliages, Villarssur-Olion, Suisse, Centre National de la Recherche Scientifique, c. 7, p. 99, 394 - 493 Sept., 1975.

4 Reis GS. Influência da microestrutura e das condições de deformação nas curvas de escoamento plástico de aços inoxidáveis duplex no ensaio de torção a quente [tese de doutorado]. São Carlos: Universidade Federal de São Carlos; 1999.

5 Mcqueen HJ, Ryan ND. Constitutive analysis in hot working. Montreal: Mechanical Engineering, Concordia University; 2002.

6 Sellars CM, Mctegart WJ. Relation Between Strength and, Structure in Deformation at Elevated Temperatures. Mem. Sci. Rev. Met. 1966;9:731.

7 Decarli CCM. Estudo quantitativo da correlação entre microestrutura e comportamento de escoamento plástico de aços inoxidáveis duplex [tese de doutorado]. São Carlos: Universidade Federal de São Carlos; 2003.

8 Hornbogen E. On the microstructure of alloys. Acta Metallurgica. 1984;32:615.

9 Balancin O, Hoffmann WAM, Jonas JJ. Influence of microstructure on the flow behavior of duplex stainless steels at high temperatures. Metallurgical and Materials Transactions A. 2000;31A:1353.

10 Cizek P, EK, Wynne BPA. A mechanism of ferrite softening in a duplex stainless steel deformed in hot torsion. Mat. Sci. Eng. 1997;A230:88-94.

11 Richards P, Sheppard T. Development of structure and effect of processing parameters on strength-structure relationships for two ferritic stainless steels. Materials Science and Technology. 1986;2:836-840.

\footnotetext{
* Contribuição técnica ao $69^{\circ}$ Congresso Anual da ABM - Internacional e ao 14ํㅡㄹ ENEMET - Encontro Nacional de Estudantes de Engenharia Metalúrgica, de Materiais e de Minas, 21 a 25 de julho de 2014, São Paulo, SP, Brasil.
} 